\title{
Fatigue Strengths of Particulate Filler Composites Reinforced with Fibers
}

\author{
Ji-Myung BAE ${ }^{1}$, Kyoung-Nam KIM ${ }^{2}$, Masayuki HATTORI ${ }^{3}$, Koji HASEGAWA ${ }^{3}$, Masao YOSHINARI ${ }^{3}$, \\ Eiji KAWADA ${ }^{3}$ and Yutaka ODA ${ }^{3}$ \\ ${ }^{1}$ Department of Dental Biomaterials, College of Dentistry, Wonkwang University, 344-2 ShinYong-dong, Iksan-city, Jeonbuk, \\ 570-749, Korea \\ ${ }^{2}$ Department and Research Institute of Dental Biomaterials and Bioengineering, College of Dentistry, Yonsei University, 134 \\ Shinchon-dong, Sudaemoon-ku, Seoul, 120-752, Korea \\ ${ }^{3}$ Department of Dental Materials Science, Tokyo Dental College, 1-2-2 Masago, Mihama-ku, Chiba-city, 261-8502, Japan \\ Corresponding author, E-mail:baejimy@wonkwang.ac.kr
}

Received January 13, 2004/Accepted March 19, 2004

\begin{abstract}
The aim of this study was to evaluate the dynamic fatigue strengths at $10^{5}$ cycles and the strains of particulate filler composite resins with and without reinforcing fibers. An UHMWPE (Ribbond), a polyaromatic polyamide fiber (Fibreflex), and three glass fibers (GlasSpan, FibreKor, Vectris Frame) were used to reinforce the particulate filler composite resins. The fatigue properties were measured in three-point bending mode using a servohydraulic universal testing machine at a frequency of $5 \mathrm{~Hz}$, until failure occurred or $10^{5}$ cycles had been completed. The fatigue strengths at $10^{5}$ cycles were determined by the staircase method. The fractured aspects of specimens were evaluated by an optical and scanning electron microscope. The fatigue strengths of particulate filler composite resins were 49-57 MPa, and those of fiber-reinforced were 90-209 MPa. Unidirectional glass fibers showed higher reinforcing effects on the fatigue strengths of composite resins. The strain of UHMWPE-reinforced composite was largest.
\end{abstract}

Key words: Fiber-reinforced composite, Dynamic fatigue strength, 3-point bending

\section{INTRODUCTION}

A composite is a multiphase material that is artificially made and separated by a distinct interface. Many composite materials are composed of two phases; one is the matrix, which is continuous and surrounds the other phase which is filler, often called the dispersed phase ${ }^{1)}$. The dispersed phase can be particle or fiber. The reinforcing efficiency of fibers depends on the component and geometric orientation of fiber, the ratio of fiber to resin, and the adhesion between fiber and resin matrix ${ }^{2-4)}$. Cilass fiber has a high strength but its elastic modulus is not so high, while carbon fiber is relatively stiff. Polyaramid fiber is also strong and stiff ${ }^{1)}$. The rnechanical properties, particularly the impact strength of UHMWPE (ultra high molecular weight polyethylene) fiber is known to be better compared with those of glass fibers ${ }^{5)}$. The demand for restorations using these fibers, which can replace the metal substructure, has increased due to their advantages like higher esthetic property, simple laboratory procedure, and being free of corrosion and metal allergy ${ }^{6)}$. They can be used in periodontal splints, fixation of avulsed teeth, endodontic posts, reinforcement of denture frameworks and orthodontic appliances, aind fixed partial dentures in the dental field ${ }^{7)}$.

In a previous paper, we reported on the flexural strength and elastic modulus of FRC (fiberreinforced composite) in a static test ${ }^{7)}$. However, the stress applied in the mouth is gerierally low and repeated rather than being a single impact. It is estimated that the intraoral stress received by dental restorations during mastication is repeated more than $3 \times 10^{5}$ times per year ${ }^{8)}$. From this viewpoint, it might be more appropriate to estimate the strength of dental prosthesis based on the fatigue property rather than static. As in the previous paper, we made specified specimens according to ISO specification $10477^{9)}$, in order to evaluate the effect of fiber itself and to exclude the influence of design of crown and bridge on the strength and crack propagation.

Fatigue is a form of failure that occurs in structures subjected to dynamic and fluctuating stresses. Under those circumstances it is possible for failure to occur at a stress level considerably lower than the tensile or yield strength for a static load. The fatigue failure mechanism in fiber-reinforced composites is quite different from those in monolithic, homogeneous materials such as metals. The damage in FRC accelerates and then decelerates with cycling, while it accelerates monotonically in homogeneous materials $^{2)}$. The factors that affect fatigue life include mean stress level, geometrical design, surface effects, and environment ${ }^{1,10)}$. Fatigue properties are potentially sensitive to degradation in an aqueous environment by the plasticization effect of water ${ }^{11-13)}$. We hypothesize that dynamic fatigue results in fibermatrix debonding and a reduction of flexural strength in a static test.

The aim of this study was to evaluate the reinforcing effects of various fibers on particulate filler 
composite resins by repeated loading. By obtaining the fatigue strength of FRC at $10^{5}$ cycles, the relationship between static flexural strength and fatigue strength was investigated.

\section{MATERIALS AND METHODS}

\section{Specimen preparation}

The materials used in this study including five brands of fibers and four kinds of particulate filler composite resins are explained in Table 1. The SEM images of five fibers are shown in Figs. 1 and 2. The schematic diagram of the FRC test specimen is described in Fig. 3. A UHMWPE fiber (RB), a polyaromatic polyamide fiber $(\mathrm{FF})$, and three glass fibers (FK, GS, and VF) were used. VF is a bidirectional fiber weave, while the others are continuous unidirectional fibers. One layer of each fiber

Table 1 Materials Used in the Study

\begin{tabular}{|c|c|c|c|c|c|}
\hline Brand name & Code & Manufacturer & Lot number & Primary composition & $\begin{array}{c}\text { Type } \\
\text { (Diameter, } \mu \mathrm{m} \text { ) }\end{array}$ \\
\hline Ribbond & $\mathrm{RB}$ & $\begin{array}{l}\text { Ribbond Inc. } \\
\text { WA, U.S.A. }\end{array}$ & 9518 & UHMWPE & $\begin{array}{l}\text { Leno-woven ribbon } \\
(10-15)\end{array}$ \\
\hline GlasSpan & GS & $\begin{array}{l}\text { GlasSpan Inc. } \\
\text { PA, U.S.A. }\end{array}$ & 990101 & E-glass & $\begin{array}{l}\text { Braided ribbon } \\
(4-6)\end{array}$ \\
\hline Fibreflex & $\mathrm{FF}$ & $\begin{array}{r}\text { BioComp } \\
\text { CA, U.S.A. }\end{array}$ & 9801 & $\begin{array}{l}\text { Polyaromatic } \\
\text { polyamide } \\
(\text { Kevlar-49) }\end{array}$ & $\begin{array}{l}\text { Unidirectional tuft } \\
(13-17)\end{array}$ \\
\hline FibreKor & FK & $\begin{array}{l}\text { Jeneric/Pentron } \\
\text { CT, U.S.A. }\end{array}$ & 18529 & S-glass & $\begin{array}{l}\text { Unidirectional fiber } \\
\text { Pre-impregnated in } \\
\text { Bis-GMA }(6-9)\end{array}$ \\
\hline Vectris Frame & $\mathrm{VF}$ & $\begin{array}{l}\text { Ivoclar/Vivadent } \\
\text { Liechtenstein }\end{array}$ & 895033 & E-glass & $\begin{array}{l}\text { Bi-directional woven sheet } \\
\text { Pre-impregnated in } \\
\text { Bis-GMA (4-6) }\end{array}$ \\
\hline $\mathrm{C} \& \mathrm{~B}$ cement & CB & $\begin{array}{l}\text { Bisco } \\
\text { IL, U.S.A. }\end{array}$ & 9800001438 & $\begin{array}{l}\text { Bis-GMA, } \\
\text { TEG-DMA }\end{array}$ & Self-cure \\
\hline Aelitefil & $\mathrm{AF}$ & $\begin{array}{l}\text { Bisco } \\
\text { IL, U.S.A. }\end{array}$ & 9800000839 & $\begin{array}{l}\text { UDMA, } \\
\text { Bis-GMA, } \\
\text { TEG-DMA }\end{array}$ & Light-cure \\
\hline Sculpture Body & $\mathrm{SC}$ & $\begin{array}{c}\text { Jeneric/Pentron } \\
\text { CT, U.S.A. }\end{array}$ & 801902 & $\begin{array}{l}\text { PCDMA, } \\
\text { Bis-GMA }\end{array}$ & Light-cure \\
\hline Targis Dentin & $\mathrm{TD}$ & $\begin{array}{l}\text { Ivoclar/Vivadent } \\
\text { Liechtenstein }\end{array}$ & 917433 & $\begin{array}{l}\text { Bis-GMA, } \\
\text { UDMA, } \\
\text { Decandiol DMA }\end{array}$ & Light-cure \\
\hline $\begin{array}{l}\text { Dentin/Enamel } \\
\text { bonding resin }\end{array}$ & $\mathrm{DB}$ & $\begin{array}{c}\text { Bisco } \\
\text { IL, U.S.A. }\end{array}$ & 099218 & $\begin{array}{l}\text { Bis-GMA, } \\
\text { HEMA, Ketone }\end{array}$ & Light-cure \\
\hline Special resin & SB & $\begin{array}{c}\text { Jeneric/Pentron } \\
\text { CT, U.S.A. }\end{array}$ & 740941 & Bis-GMA & Light-cure \\
\hline $\begin{array}{l}\text { Targis wetting } \\
\text { agent }\end{array}$ & TW & $\begin{array}{l}\text { Ivoclar/Vivadent } \\
\text { Liechtenstein }\end{array}$ & 926398 & $\begin{array}{l}r \text {-MPTS } \\
\text { Ethanol }\end{array}$ & Self-cure \\
\hline Targis Base 2 & $\mathrm{~TB}$ & $\begin{array}{l}\text { Ivoclar/Vivadent } \\
\text { Liechtenstein }\end{array}$ & A01197 & $\begin{array}{l}\text { Bis-GMA } \\
\text { TEG-DMA }\end{array}$ & Light-cure \\
\hline
\end{tabular}

UHMWPE= ultra high molecular weight polyethylene;

DMA = dimethacrylate;

UDMA = urethane dimethacrylate;

PCDMA = polycarbonate dimethacrylate;

HEMA = hydroxyethyl methacrylate;

$\gamma$-MPTS $=[\gamma$-(methacryloxy) propyl $]$ trimethoxysilane 


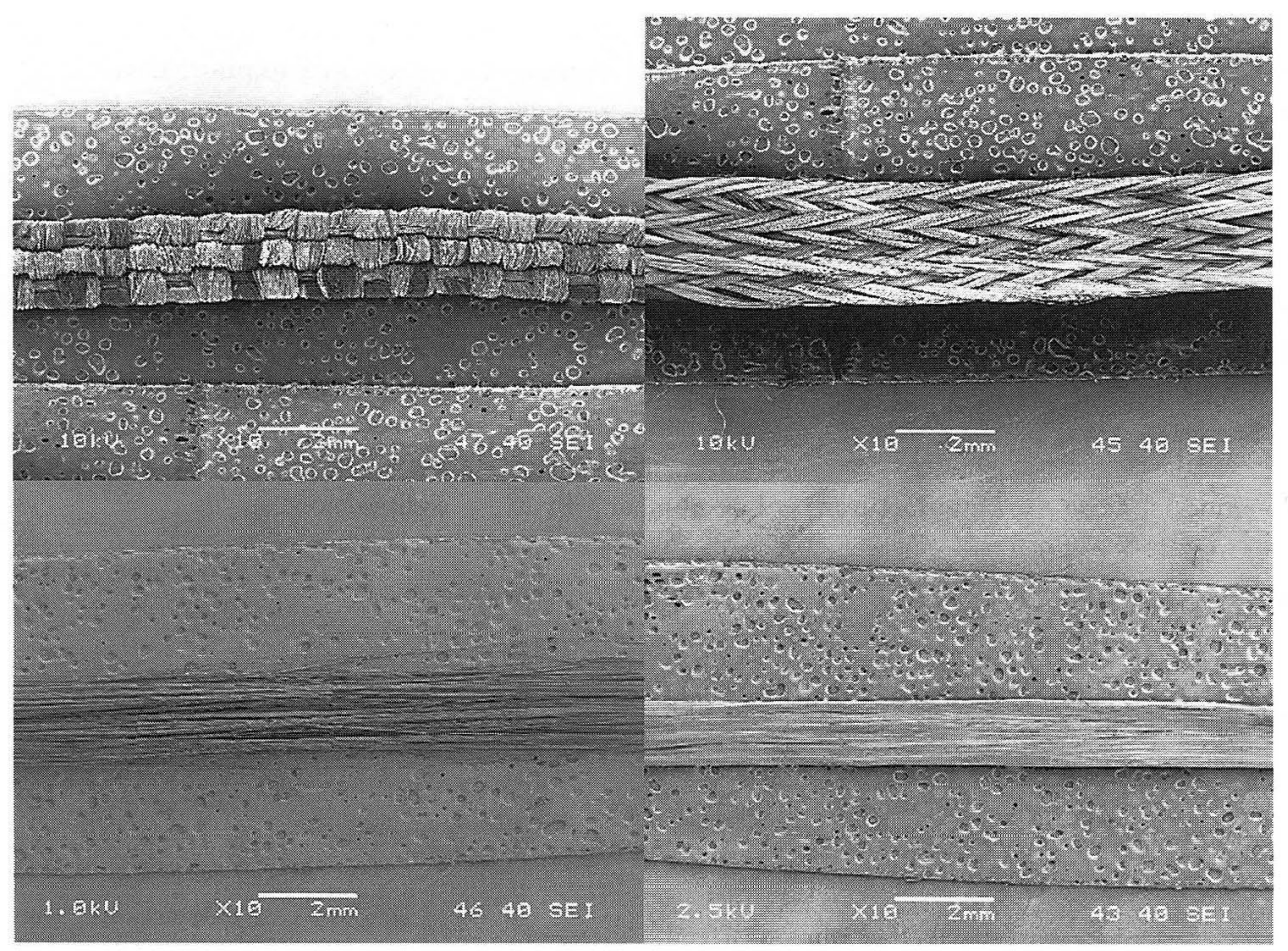

Fig. 1 Fibers used in the study (RB, GS, FK, and FF, clockwise from upper left).

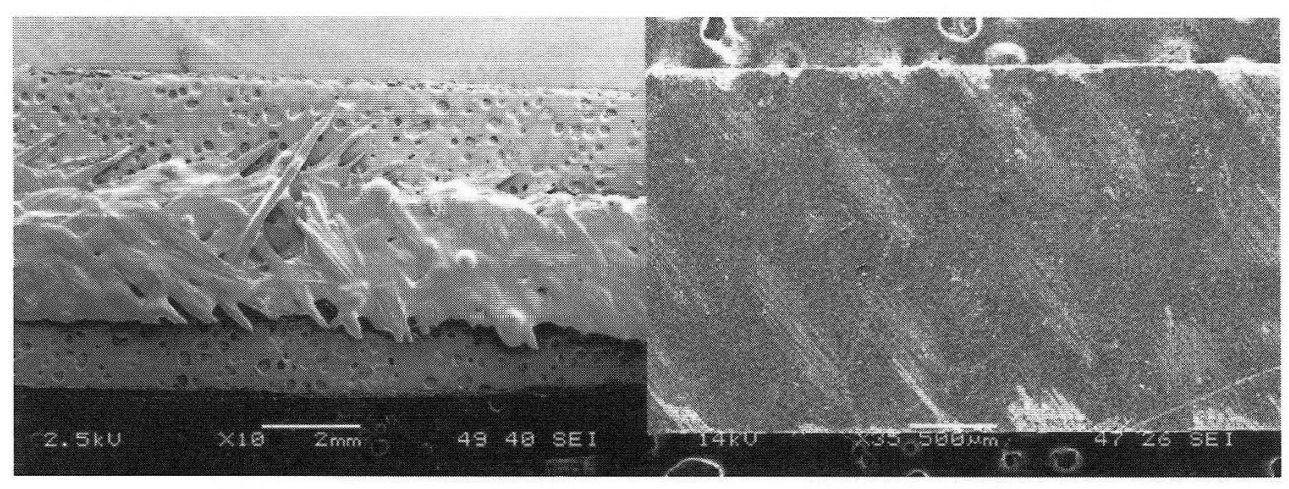

Fig. 2 SEM images of VF before curing (left) vs. VF after curing (right). Note that VF is the discontinuous and bi-directional type.

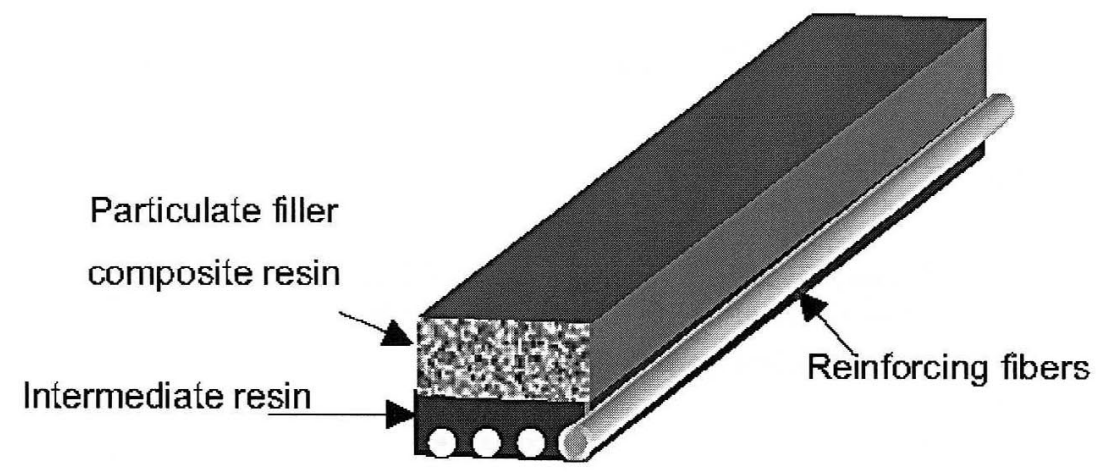

Fig. 3 Schematic diagram of a fiber-reinforced composite test specimen in the study. 


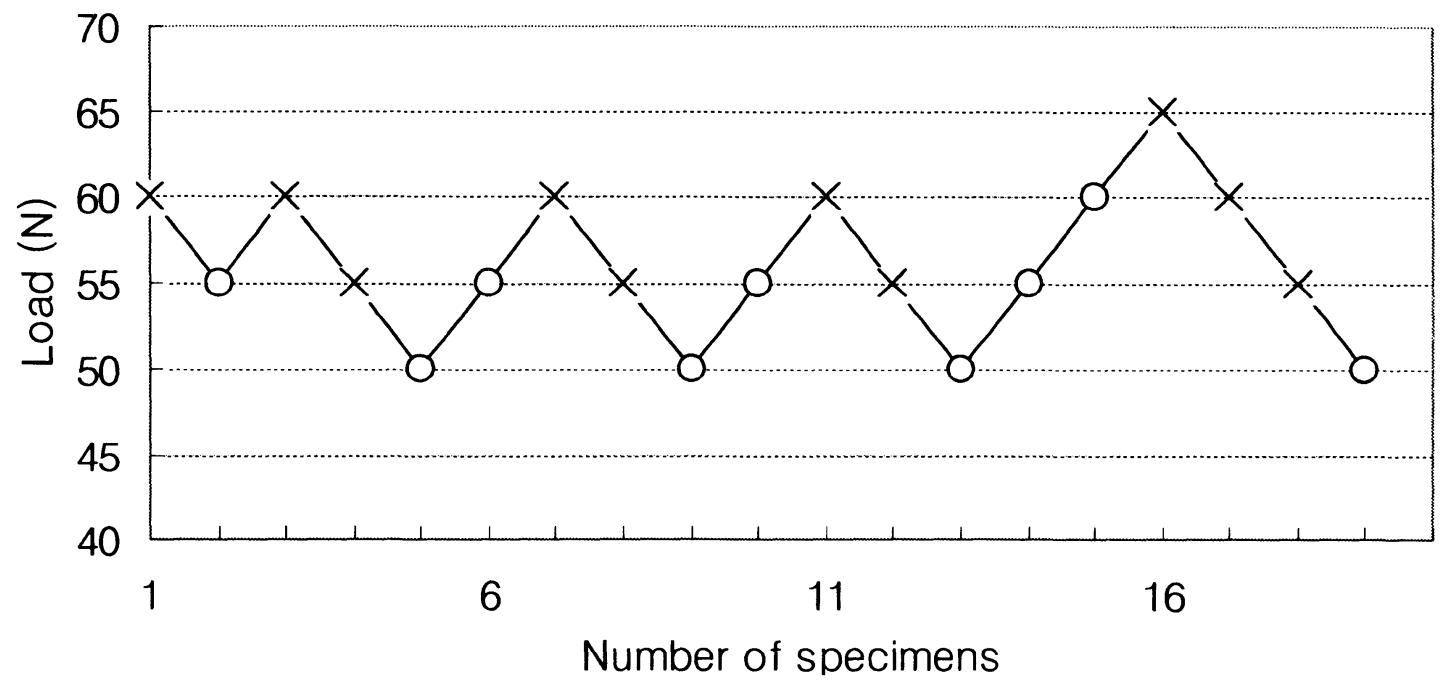

Fig. 4 Typical result of the staircase method to determine median fatigue strength at $10^{5}$ cycles for GS+AF.

$X$ : Fracture, $\bigcirc$ : Non-fracture.

Table 2 Tabular Information Required for Analyzing Mean and Standard Deviation from Staircase Method (e.g., GS+AF)

\begin{tabular}{cccccc}
\hline $\operatorname{Load}(\mathrm{N})$ & $\mathrm{i}$ & Non-fracture & Fracture & ini & $\mathrm{i}^{2} \mathrm{ni}$ \\
\hline 65 & & 1 & 0 & 0 \\
60 & 2 & 1 & 5 & 2 & 4 \\
55 & 1 & 4 & 4 & 4 & 4 \\
50 & 0 & 4 & & 0 & 0 \\
\hline \multirow{2}{*}{ Sum } & $\mathrm{N}=\sum \mathrm{ni}$ & $\mathrm{A}=\sum$ ini & $\mathrm{B}=\sum \mathrm{i}^{2} \mathrm{ni}$ \\
& $=9$ & $=6$ & $=8$ \\
\hline
\end{tabular}

In case of $\mathrm{RB}+\mathrm{CB}, \mathrm{RB}+\mathrm{AF}, \mathrm{GS}+\mathrm{CB}$, and $\mathrm{GS}+\mathrm{AF}$, a total of 19 specimens were used, while 20 specimens were tested for the other groups.

was located in the mold $(25 \mathrm{~mm} \times 2 \mathrm{~mm} \times 2 \mathrm{~mm})$ to be the tension side of the specimen. For both FK and $\mathrm{VF}$, which are preimpregnated in Bis-GMA, their own intermediate resin (IMR) and particulate filler composite resins were used, respectively: $\mathrm{SB}$ and $\mathrm{SC}$ (shade: A1) for FK; and TW followed by TB and TD for VF (shade: 210). In the case of the other fibers, DB was applied and cured for 20 seconds for interfacial treatment, and AF (shade: A1) was polymerized on it for 40 seconds with Curing Light XL 3000 $(3 \mathrm{M})$. In RB and GS, CB (shade: opaque), which could be used as a luting cement for fiber post, was additionally used. The non-reinforced specimens of particulate filler composite resins were made the same size as above, without fibers. All the specimens were made in the same manner as previously reported ${ }^{7)}$. Twenty specimens of each group were prepared and stored in distilled water at $37^{\circ} \mathrm{C}$ for $24 \mathrm{hrs}$ before testing according to ISO $10477^{9)}$.

\section{Fatigue test}

A servohydraulic universal testing machine (EHF-
F05, Shimadzu, Japan) was used to evaluate the fatigue strength in the three-point bending mode at a frequency of $5 \mathrm{~Hz}$, until failure occurred or until $10^{5}$ cycles had been completed in a water bath of 37 ${ }^{\circ} \mathrm{C}$. The fiber part of the specimen was located on the tension side with two supports at a distance of $20 \mathrm{~mm}$.

The staircase method, with a stress increment of $2 \mathrm{~N}$ for composite resin and $5 \mathrm{~N}$ for FRC, except $\mathrm{VF}+\mathrm{TD}(2.5 \mathrm{~N}$ load increment), was used to determine the fatigue strength. When the first specimen was broken at less than $10^{5}$ cycles, another specimen was applied at a stress level one increment lower. If it was not fractured under a $10^{5}$ cyclic load, another specimen was applied with a load one increment higher $^{14,15)}$. This procedure was continued, until twenty specimens of each group were expended. A typical result of the staircase method to determine median (mean) fatigue strength is shown in Fig. 4.

The calculation of the mean and standard deviation of the fatigue strength is determined via the staircase method by the following equations ${ }^{14,15}$ ) 
(Table 2).

$$
m=y^{\prime}+d[\mathrm{~A} / \mathrm{N}(+ \text { or }-) 1 / 2]
$$$$
s=1.620 d\left[\left(\mathrm{NB}-\mathrm{A}^{2}\right) / \mathrm{N}^{2}+0.029\right] \text { if }\left(\mathrm{NB}-\mathrm{A}^{2}\right) / \mathrm{N}^{2} \geq 0.3
$$

where, $m=$ statistical estimate of mean fatigue strength

$y^{\prime}=$ lowest stress level at which the less frequent event occurred

$d=$ step size, i.e. the stress increment

$\mathrm{N}=$ total number of less frequent events

$s=$ statistical estimation of standard deviation

The plus sign $(+)$ is used if the less frequent event is non-fracture and the minus sign (-) is used if the less frequent event is fracture.

Strain was calculated using the following equation $^{16)}$ :

$$
\varepsilon=\frac{6 \delta \mathrm{h}}{\mathrm{L}^{2}}
$$

where, $\varepsilon$ is strain, $\delta$ is deflection, $h$ is the thickness of specimen and $\mathrm{L}$ is the length of span. Obtained data of strain were analyzed by one-way analysis of variance (ANOVA) and by the Sheffé method for multiple comparison at the $P=0.05$ level.
Optical microscopic and SEM observations

After testing, the fractured aspects were evaluated by an optical microscope (Hi-Scope, KH-1000, Hirox Co., Ltd., Japan) at $120 \times$ magnification using a computer program (Image-Pro ${ }^{\circledR}$ Plus, Version 4.1, Media Cybernetics, U.S.A.). The fractured surfaces and the cross-sections embedded in epoxy resin were evaluated by a Field Emission Scanning Electron Microscope (JSM-6340F, JEOL DATUM, Japan) at 50 $\times$ and $3,000 \times$ magnifications.

\section{RESULTS}

\section{Fatigue test}

The dynamic fatigue strengths at $10^{5}$ cycles and strains of particulate filler composite resins without $\left(\mathrm{FF}_{0}\right)$ and with reinforcing fibers $\left(\mathrm{FF}_{r}\right)$ are listed in Table 3. The fatigue strengths of the composite resins at $10^{5}$ cycles were $49-57 \mathrm{MPa}$, while those of FRC were about $90-200 \mathrm{MPa}$. The fatigue strengths of glass fiber-reinforced composites were higher than other FRC, except for the VF-reinforced one which is a discontinuous and bi-directionally arranged fiber.

Table 3 Fatigue Strengths and Strains of Particulate Filler Composites with

\begin{tabular}{|c|c|c|c|c|c|c|}
\hline \multirow{2}{*}{ Resin } & \multirow{2}{*}{ Fiber } & \multicolumn{2}{|c|}{ Strain $(\%)$} & \multicolumn{2}{|c|}{ Fatigue strength $(\mathrm{MPa})$} & \multirow{2}{*}{$\begin{array}{l}\left(\mathrm{FF}_{r} / \mathrm{FF}_{0}\right) \\
\times 100(\%) \\
\end{array}$} \\
\hline & & Resin & FRC & Resin, $\mathrm{FF}_{0}$ & $\mathrm{FRC}, \mathrm{FF}_{r}$ & \\
\hline \multirow{2}{*}{$\mathrm{CB}$} & $\mathrm{RB}$ & \multirow{2}{*}{$0.4 \pm 0.1^{\mathrm{b}}$} & $6.4 \pm 2.0^{\mathrm{a}}$ & \multirow{2}{*}{$48.8 \pm 7.0$} & $167.7 \pm 15.1$ & 344 \\
\hline & GS & & $1.1 \pm 0.2^{\mathrm{c}}$ & & $201.0 \pm 19.6$ & 412 \\
\hline \multirow{3}{*}{$\mathrm{AF}$} & $\mathrm{RB}$ & \multirow{3}{*}{$0.2 \pm 0.1^{\mathrm{c}}$} & $5.9 \pm 2.6^{\mathrm{b}}$ & \multirow{3}{*}{$54.6 \pm 5.2$} & $134.4 \pm 14.4$ & 246 \\
\hline & GS & & $0.8 \pm 0.0^{c}$ & & $209.4 \pm 14.4$ & 384 \\
\hline & $\mathrm{FF}$ & & $0.9 \pm 0.4^{c}$ & & $178.1 \pm 16.1$ & 326 \\
\hline $\mathrm{SC}$ & FK & $0.2 \pm 0.1^{\mathrm{c}}$ & $0.5 \pm 0.1^{\mathrm{c}}$ & $57.2 \pm 16.9$ & $196.9 \pm 19.1$ & 344 \\
\hline $\mathrm{TD}$ & VF & $0.5 \pm 0.2^{\mathrm{a}}$ & $0.8 \pm 0.2^{c}$ & $56.3 \pm 18.6$ & $90.2 \pm 9.7$ & 160 \\
\hline
\end{tabular}
and without Reinforcing Fibers (Mean \pm Standard Deviation)

\begin{tabular}{|c|c|c|c|c|c|c|}
\hline & $\begin{array}{l}\text { No. of } \\
\text { fractured } \\
\text { specimens }\end{array}$ & $\begin{array}{l}\text { Fiber } \\
\text { fracture }\end{array}$ & $\begin{array}{l}\text { Completely } \\
\text { cut into } \\
\text { two }\end{array}$ & $\begin{array}{l}\text { * One part: } \\
\text { adhered, } \\
\text { The other: } \\
\text { delaminated }\end{array}$ & $\begin{array}{l}{ }^{*} \text { The middle: } \\
\text { resin } \\
\text { chopped out }\end{array}$ & $\begin{array}{c}\text { Bending } \\
\text { toward the } \\
\text { direction of } \\
\text { load }\end{array}$ \\
\hline $\mathrm{RB}+\mathrm{CB}$ & 9 & No & & & 9 & 9 \\
\hline $\mathrm{RB}+\mathrm{AF}$ & 9 & No & & & 9 & 9 \\
\hline $\mathrm{GS}+\mathrm{CB}$ & 10 & Yes & 8 & 2 & & \\
\hline $\mathrm{GS}+\mathrm{AF}$ & 10 & Yes & 10 & & & \\
\hline $\mathrm{FF}+\mathrm{AF}$ & 10 & No & & 10 & & 10 \\
\hline $\mathrm{FK}+\mathrm{SC}$ & 11 & No & & 11 & & \\
\hline $\mathrm{VF}+\mathrm{TD}$ & 12 & Yes & 12 & & & \\
\hline \multicolumn{7}{|c|}{$\begin{array}{l}\text { * One part of fiber adhered to the particulate filler composite resin, while the other part } \\
\text { fiber delaminated from it. } \\
\text { * The middle portion of particulate filler composite resin fractured out with a lot of crack } \\
\text { without the involvement of reinforcing fibers. }\end{array}$} \\
\hline
\end{tabular}

Table 4 Fractured Aspects of Specimens after Repeated Loading 


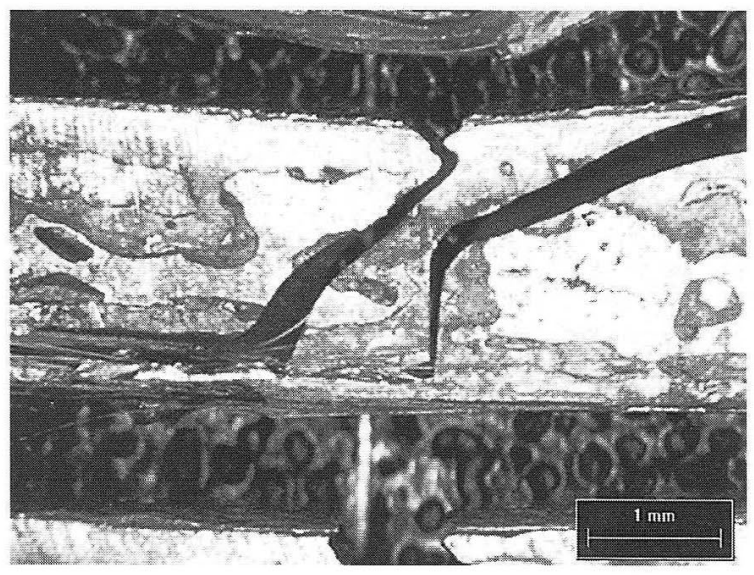

Fig. 5 Fractured aspect of FK + SC (original magnification $\times 120$ ).

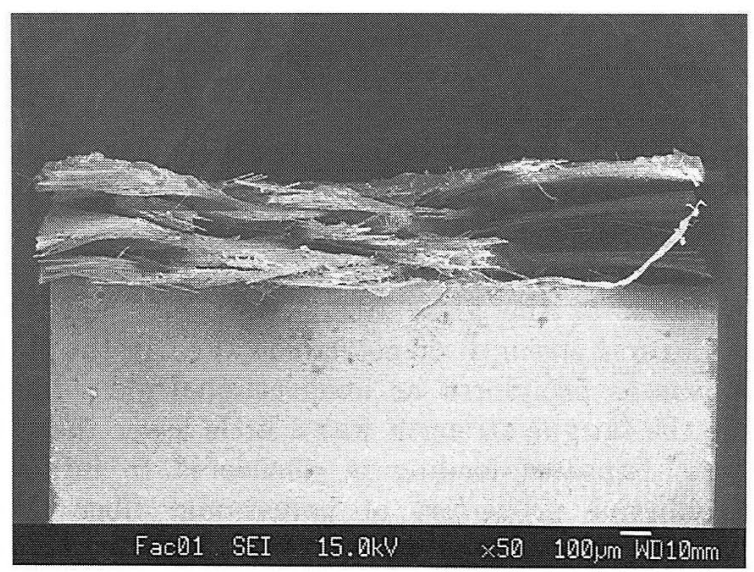

Fig. 7 Fractured surface of VF+TD in cross-section.

In terms of the reinforcing effects $\left(\mathrm{FF}_{r} / \mathrm{FF}_{0}\right)$, the FRC with $\mathrm{CB}$ matrix showed a higher reinforcing effect than that with AF matrix in both RB- and GSreinforced composites.

The strains of RB-reinforced composites showed the largest values and those of other FRC were not significantly different $(P<0.05)$.

\section{Optical microscopic and SEM observations}

The fractured aspects of FRC after repeated loading were shown as an optical microscopic image $(120 \times)$ in Fig. 5. Table 4 explains the fracture characteristics of fractured specimens based on the relationship between fiber and particulate filler composite resin. All the specimens of GS- and VF-reinforced composites were completely cut into two, including fibers. However, in RB-, FF-, and FK-reinforced ones, the fiber portions were sustained, although the overlying composite resins (the matrix) were broken in the middle.

In a cross-section of RB-reinforced composite embedded in epoxy resin, the fiber part was observed to

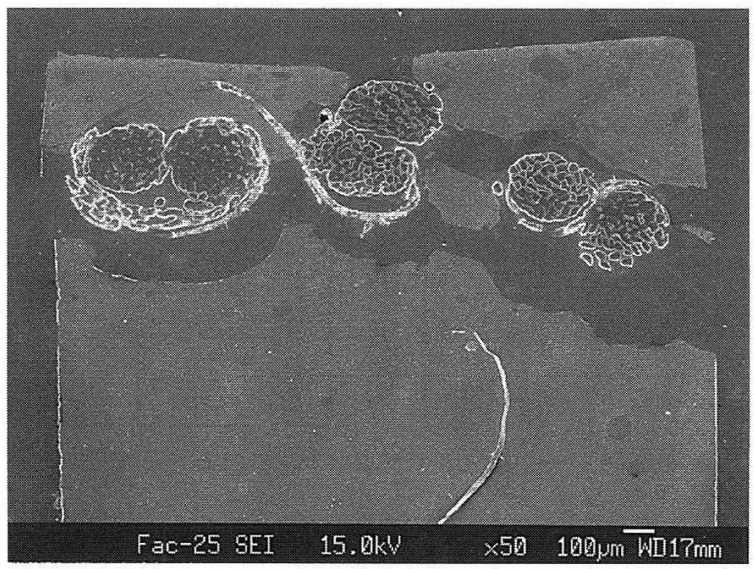

Fig. 6 Cross-section of $\mathrm{RB}+\mathrm{AF}$ embedded in epoxy resin.

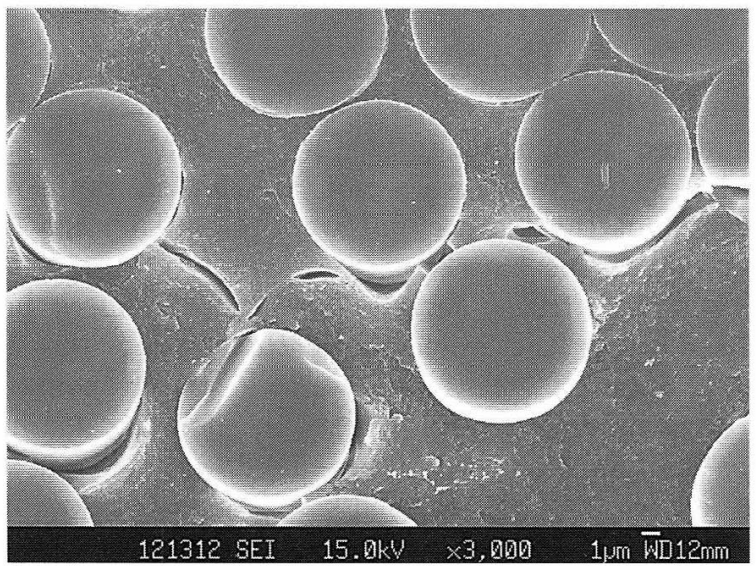

Fig. 8 Cross-section of FK+SC embedded in epoxy resin.

be delaminated from the matrix after repeated loading (Fig.6). In glass fiber-reinforced composites, fewer cracks were noted along the fibers than in the FF-reinforced one (Fig. 8).

Fig. 7 shows a representative SEM image of the fractured surface of FRC. GS- and VF-reinforced composites showed good adhesive properties between fiber and the matrix. For FF- and FK-reinforced ones, the adhered part of fiber to the matrix showed rather good adhesive properties, while most of the fibers were pulled out of the matrix in the delaminated part.

\section{DISCUSSION}

This study was carried out to evaluate the fatigue strengths at $10^{5}$ cycles and the strains of particulate filler composite resins with and without reinforcing fibers, which could be a guide to the study using FRC. In most previous studies related to FRC, the specimens were made of fibers and the matrix with unfilled resin ${ }^{17-19)}$. However, when FRC is applied to 


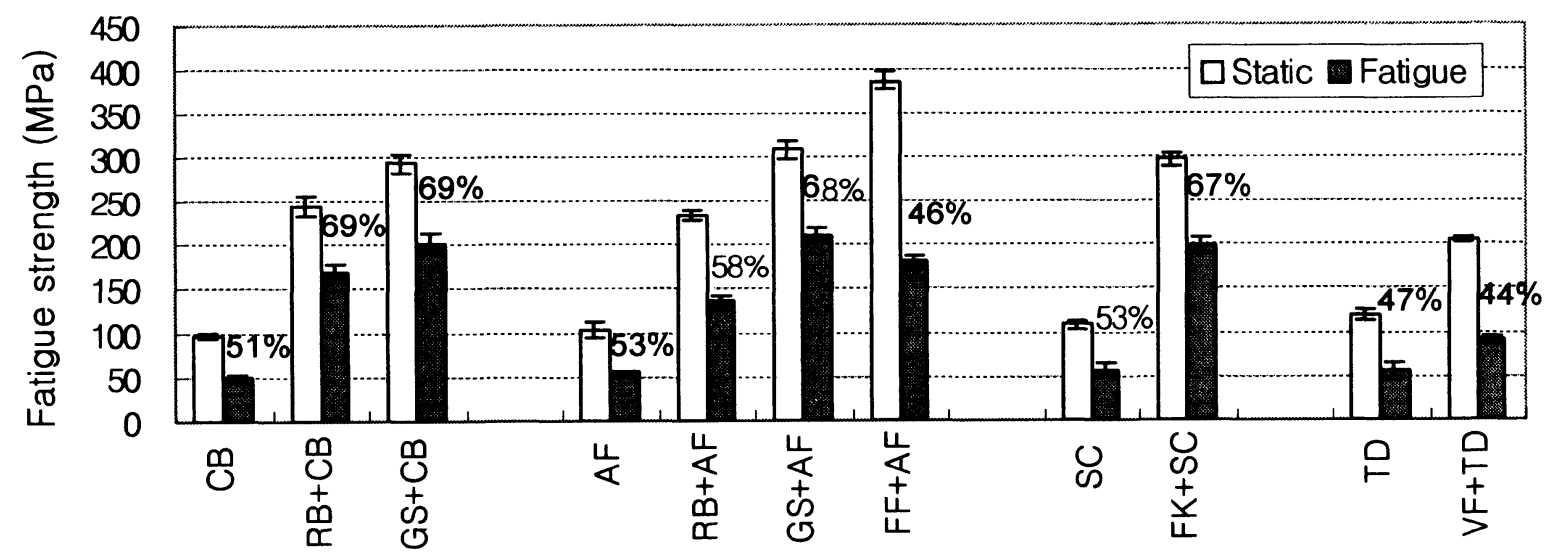

Fig. 9 Fatigue strength at $10^{5}$ cycles vs. static ultimate flexural strength of particulate filler composite resin with and without reinforcing fibers.

the crown and bridge, the particulate filler composite resin is generally used. We adopted ceramic particlereinforced composite resin for the matrix in this study. The fibers were not distributed uniformly throughout the matrix, but were located on the tension side of the matrix.

Many different fatigue testing procedures have been devised; the standard method using the $S-N$ curve, constant stress level testing, the response or survival method (Probit method), step-test method, Prot method, staircase or up-and-down method, and the extreme value method ${ }^{14)}$. Among these, the "staircase method" automatically concentrates testing near the mean and requires fewer tests ${ }^{20,21)}$, which is equally valid for determining the fatigue limit ${ }^{14)}$. In particular, when $\left(\mathrm{NB}-\mathrm{A}^{2}\right) / \mathrm{N}^{2}$ is larger than 0.3 , the estimation of standard deviation becomes more accurate $^{14,15)}$. All the coefficients $(0.47$ for $\mathrm{RB}+\mathrm{CB}, 0.62$ for $\mathrm{GS}+\mathrm{CB}, 0.44$ for $\mathrm{RB}+\mathrm{AF}, 0.44$ for $\mathrm{GS}+\mathrm{AF}, 0.53$ for $\mathrm{FF}+\mathrm{AF}, 0.60$ for $\mathrm{FK}+\mathrm{SC}$, and 0.61 for $\mathrm{VF}+\mathrm{TD}$ ) were larger than 0.3 in this study.

According to Draughn ${ }^{22)}$, the fatigue strength of composite resin was applicable to $64 \%$ of compressive strength in the static test. The fatigue strengths of composite resins in this study occurred at stress levels relative to the yield flexural strengths of static test from previous study ${ }^{7)}$, as with polymers mentioned by Callister ${ }^{1)}$. However, the fatigue strengths of FRC were about $60-70 \%$ of ultimate flexural strengths, except FF- and VF-reinforced composites, which were about $45 \%$ of the static values ${ }^{7)}$ (Fig. 9). The fatigue strengths of glass fiber-reinforced composites were higher than other fiber-reinforced composites except VF. Some critical fiber length is necessary for effective strengthening and stiffening of the composite material ${ }^{1,23)}$. For this purpose, continuous fiber rather than discontinuous or short fiber is effective ${ }^{24)}$. The strength of FRC is highly anisotropic, meaning that it had marked preference for any particular direction ${ }^{2,23,25)}$. In this viewpoint of short fiber composition and bi-directional arrangement, VF is considered to result in low fatigue strength, in spite of the fair impregnated state confirmed by SEM (Fig. 2).

SEM observations indicated good aspects of impregnation of the glass fibers (GS, FK, and VF). The flexural strength of polyamide $(\mathrm{FF})$ in the static test was as prominent as unidirectional glass fibers, while the fatigue strength was a little lower than the latter. Repeated loading is considered to influence the adhesive properties of polyaramid fiber much more than glass fibers. The lack of adhesion between UHMWPE (RB) fiber and IMR even after plasma spray treatment of the surface ${ }^{5,17)}$ seemed to be pronounced after repeated loading (Fig. 6), and it could be the cause of the lower fatigue value. For polymer-matrix composite, failure originates in or along the reinforcing fibers ${ }^{23)}$. It is essential to get a high interfacial strength to maximize the overall strength of $\mathrm{FRC}^{6,26,27)}$. Although it was suggested that polymer preimpregnation of fiber should have better impregnation ${ }^{18,28,29)}$, the differences between preimpregnation and non-preimpregnation in fatigue strengths were not recognized in this study, as previously reported ${ }^{7)}$.

The strain of RB-reinforced composites showed the largest values $(P<0.05)$. If the strain of a material is large, despite its fatigue strength being rather high, it is difficult to apply it to dental use. The actual meaningful strengths are assumed to be lower than the evaluated fatigue strength, because a large deformation and cracks occurred before catastrophic failure.

In a previous study, we reported a method of determining fiber volume content ${ }^{7)}$. For RB, GS, and $\mathrm{FF}$, the weights of fibers were measured. For preimpregnated fibers, FK and VF, the weights of fibers were determined by combustion for 45 minutes 
at $700^{\circ} \mathrm{C}$ and the fiber content as percentage by volume $\left(\mathrm{V}_{f}\right)$ (vol\%) was calculated with the following formula ${ }^{30)}$ :

$$
\mathrm{V}_{f}=\frac{\mathrm{W}_{f} / \rho_{f}}{\mathrm{~W}_{f} / \rho_{f}+\mathrm{W}_{r} / \rho_{r}} \times 100
$$

where $\mathrm{W}_{f}$ is the weight proportion of fiber, $\rho_{f}$ is the density of fiber, $\mathrm{W}_{r}$ is the weight proportion of resin, and $\rho_{r}$ is the density of resin. The fiber volume contents of the FRC were $9.07 \pm 0.34 \%$ for $\mathrm{RB}$ in $\mathrm{CB}$, $8.60 \pm 0.26 \%$ for $\mathrm{RB}$ in $\mathrm{AF}, 6.33 \pm 0.50 \%$ for $\mathrm{VF}$ in $\mathrm{TD}, 4.14 \pm 0.06 \%$ for $\mathrm{FK}$ in SC, $3.96 \pm 0.08 \%$ for GS in $\mathrm{CB}, 3.92 \pm 0.13 \%$ for $\mathrm{GS}$ in $\mathrm{AF}$, and $2.93 \pm 0.06 \%$ for $\mathrm{FF}$ in $\mathrm{AF}^{7)}$. Because only a strip of each fiber as supplied by manufacturer was used in the study, the volume contents of $\mathrm{RB}$ and $\mathrm{VF}$ were larger than others. However, the volume contents between unidirectional glass fibers and polyaramid fiber were not much different. Further study is necessary to control the fiber contents to get more accurate results.

In the combination of reinforcing fiber and overlying particulate filler composite in this study, the interfacial adhesion and matching of flexural modulus of these two phases must have played an important role. To increase the mechanical properties of this kind of material, further research should be conducted to improve the interfacial bond strength. A new fiber-reinforced composite material, the hybrid, which means more than two kinds of fiber used in a single matrix in various arrangements, has been introduced to improve mechanical properties $^{1,23)}$. This hybrid type is considered to be necessary in the dental field, too. In combination of glass fibers with carbon or polyaramid fiber would be stronger and tougher, and it could increase the clinical success rate of FRC.

\section{ACKNOWLEDGEMENTS}

The authors wish to thank the Hakusui Corporation for equipment support and helpful advice. We also would like to acknowledge our appreciation for Pf. Bales from University of Washington, Pf. KwangMahn Kim, and Lecturer Doug-Youn Lee from Yonsei University of Korea for their valuable advice and help. We express our gratitude to HanKuk Fiber Inc. for supplying basic data and E-glass fibers for preliminary research.

\section{REFERENCES}

1) Callister WD Jr. Materials science and engineering/An Introduction, 5th ed. New York: John Wiley \& Sons; 2000, p.209-225, 521-552.

2) Chawla KK. Composite materials, New York: SpringerVerlag; 1987, p.229-250.

3) Vallittu PK. Flexural properties of acrylic resin polymers reinforced with unidirectional and woven glass fibers. J Prosthet Dent 1999; 81: 318-326.

4) Viguie G, Malquarti G, Vincent B, Bourgeois D. Epoxy/carbon composite resins in dentistry: Mechanical properties related to fiber reinforcements. J Prosthet Dent 1994; 72: 245-249.

5) Taner B, Doğan A, Tínçer T, Akinay AE. A study on impact and tensile strength of acrylic resin filled with short ultra-high molecular weight polyethylene fibers. J Oral Sci 1999; 41: 15-18.

6) Drummond JL, Bapna MS. Static and cyclic loading of fiber-reinforced dental resin. Dent Mater 2003; 19: 226231.

7) Bae JM, Kim KN, Hattori M, Hasegawa K, Yoshinari M, Kawada E, Oda Y. The flexural properties of fiberreinforced composite with light-polymerized polymer matrix. Int $J$ Prosthodont 2001; 14: 33-39.

8) Kato H. Fatigue properties of dental alloys $/ 12 \% \mathrm{Au}-$ $\mathrm{Pd}-\mathrm{Ag}$ alloy and type III gold alloy. Aichi-Gakuin J Dent Sci 1989; 27: 1017-1027.

9) International Standards Organization. ISO 10477-1992 (E): Polymer-based crown and bridge materials. Geneva: ISO, 1992.

10) Baran GR, McCool JI, Paul D, Boberick K, Wunder S. Weibull models of fracture strengths and fatigue behavior of dental resins in flexure and shear. J Biomed Mater Res (Appl Biomater) 1998; 43: 226-233.

11) Gladys S, Braem M, Meerbeek BV, Lambrechts $P$, Vanherle G. Immediate versus one-month wet storage fatigue of restorative materials. Biomaterials 1998; 19: 541-544.

12) Lassila LVJ, Nohrström T, Vallittu PK. The influence of short-term water storage on the flexural properties of unidirectional glass fiber-reinforced composites. Biomaterials 2002; 23: 2221-2229.

13) Rantala LI, Lastumäki TM, Peltomäki T, Vallittu PK. Fatigue resistance of removable orthodontic appliance reinforced with glass fibre weave. J Oral Rehabil 2003; 30: 501-506.

14) Collins JA. Failure of materials in mechanical design: Analysis, Prediction, Prevention. New York: John Wiley \& Sons; 1981, p.360-378.

15) Dixon WJ, Mood AM. A method for obtaining and analyzing sensitivity data. J Am Stat Ass 1948; 43: 109-126.

16) Oda Y, Matsuno S, Sakurai Y. Tensile, compressive and bending yield strength of various dental casting alloys. J Japan Soc Dent Mat Dev 1984; 3: 465-470.

17) Ellakwa AE, Shortall AC, Shehata MK, Marquis PM. Influence of bonding agent composition on flexural properties of an ultra-high molecular weight polyethylene fiber-reinforced composite. Operative Dent 2002; 27: 184-191.

18) Lastumäki TM, Kallio TT, Vallittu PK. The bond strength of light-curing composite resin to finally polymerized and aged glass fiber-reinforced composite substrate. Biomaterials 2002; 23: 4533-4539.

19) Vallittu PK. Acrylic resin-fiber composite - part II: The effect of polymerization shrinkage of polymethyl methacrylate applied to fiber roving on transverse strength. J Prosthet Dent 1994; 71: 613-617. 
20) Little RE, Jebe EH. Fitting the $P-S$ curve: Statistical design of fatigue experiments. New York-Toronto: A Halsted Press Book, A division of John Wiley \& Sons; 1975, p.168-197.

21) Yamamoto $M$, Takahashi $H$. Tensile fatigue strength of light cure composite resins for posterior teeth. Dent Mater J 1995; 14: 175-184.

22) Draughn RA. Compressive fatigue limits of composite restorative materials. J Dent Res 1979; 58: 1093-1096.

23) Shackelford JF. Introduction to materials science for engineers, 5th ed. Upper Saddle River: Prentice Hall International; 2000, p.280-288, p.499-535.

24) Ellakwa A, Shortall A, Shehata M, Marquis P. Influence of veneering composite composition on the efficacy of fiber-reinforced restorations (FRR). Operative Dent 2001; 26: 467-475.

25) Tezvergil A, Lassila LVJ, Vallittu PK. The effect of fiber orientation on the thermal expansion coefficients of fiber-reinforced composites. Dent Mater 2003; 19: 471-477.
26) Kallio TT, Lastumäki TM, Vallittu PK. Bonding of restorative and veneering composite resin to some polymeric composites. Dent Mater 2001; 17: 80-86.

27) Ellakwa AE, Shortall AC, Marquis PM. Influence of fiber type and wetting agent on the flexural properties of an indirect fiber reinforced composite. J Prosthet Dent 2002; 88: 485-490.

28) Kanie $T$, Fujii K, Arikawa $H$, Inoue K. Flexural properties and impact strength of denture base polymer reinforced with woven glass fibers. Dent Mater 2000; 16: 150-158.

29) Freilich MA, Karmaker AC, Burstone CJ, Goldberg AJ. Development, clinical applications of a lightpolymerized fiber-reinforced composite. J Prosthet Dent 1998; 80: 311-318.

30) Vallittu PK, Ruyter IE, Ekstrand K. Effect of water storage on the flexural properties of e-glass and silica fiber acrylic resin composite. Int $\mathrm{J}$ Prosthodont 1998; 11: $340-350$. 